\title{
Architecting Business and IS/IT Strategic Alignment for Extended Enterprises
}

\author{
Llanos Cuenca, Andrés Boza, Angel Ortiz \\ Research Centre on Production Management and Engineering (CIGIP), \\ Universidad Politécnica de Valencia Camino de Vera s/n, \\ 8G-4 (Polytechnic City of Innovation) 46022 Valencia, Spain, \\ llcuenca@cigip.upv.es, aboza@cigip.upv.es, aortiz@omp.upv.es
}

\begin{abstract}
Incorporating information systems and information technology (IS/IT) is badly needed in extended enterprises. For this purpose, the enterprise engineering approach offers important benefits; however there is no complete framework to define and model IS/IT components and their strategic alignment with the business strategy. This paper presents an enterprise architecture framework for extended enterprises which improves not only the strategic alignment process inside each individual company, but also the strategic alignment process for the extended enterprise. The main aim of this paper is to provide a modelling framework from the enterprise engineering approach which includes the components to model the IS/IT strategy and allow the extended enterprise to improve strategic alignment process. A comparative analysis has been done of life- cycle phases, modelling views and the strategic alignment between different enterprise architectures. Next, the required building blocks have been proposed: IS/IT conceptualization, strategic dependencies, alignment heuristics, maturity model and application portfolio (as-is and to-be). This proposal has been applied in the collaborative order management process of a ceramic tile company with its suppliers and consumers.
\end{abstract}

\section{Introduction}

The current economic situation and the high level of market uncertainty force companies to continuously adapt to respond to constant changes.

The competitive advantages in the changing business environment have transferred organizational structures from single enterprises to extended or virtual enterprise networks.

Collaboration among enterprises requires an efficient interaction of all the enterprise elements, which is based upon a complete framework [1]. Information technology improves the value chain (improving the enterprise processes and defining new processes) by changing the way companies do business. In this sense, it is important to define a framework to model business and, information systems, information technology (IS/IT) components, and their alignment, in an extended enterprise.

In this paper we propose a modelling framework using an enterprise engineering approach to identify views, life cycle and building blocks to model strategic alignment for extended enterprises. Business and IS/IT strategic alignment engineering is a process used for architecting and designing strategic alignment. The proposed modelling framework incorporates the elements required to fulfil this objective in early life-cycle phases.
The paper is a revised and extended version of a paper presented at BASYS'10 [2].

This paper is organized as follows: firstly, Section 2 introduces the extended enterprise and enterprise architecture concepts. Section 3 offers a review of strategic alignment. Section 4 reviews the enterprise architecture framework from the alignment perspective. Section 5 proposes the enterprise architecture framework for business and IS/IT strategic alignment in extended enterprises. Section 6 describes the proposed framework which has been applied in a ceramic tile company. Finally, Section 7 provides the concluding remarks.

\section{Extended Enterprises and Enterprise Architecture}

Nowadays, many industrial organizations focus specifically on linking and unifying supply chains. This linking process leads to the synchronized behaviour of all participants [3]. They form entities, commonly called extended enterprises (EE). Extended Enterprise has been defined as: "individual companies working together to form interenterprise networks across the product value chain in order to survive and achieve business success" [4]. According to Filos [5] an Extended Enterprise (EE) refers to a single enterprise extending its boundaries to include its suppliers, consumers and partners into collaborative networks for its own benefit. 
The difference between EE and Virtual Enterprise (VE) is that the EE is controlled by the main participating enterprise whereas a VE is controlled by a common goal, and the participant can join or drop out of the VE at any time. Thus VE is a more democratic structure with peer-to-peer cooperation among participant enterprises [5]. A Supply Chain (SC) refers to a network of suppliers, producers, distributors and consumers of particular products and services. These come together to form a virtual demand chain in order to gain benefits, optimize, reduce costs and provide value addition [6]. Pires et al. [6] also argue that SC and VE differ from each other in terms of purpose, organizational structure, duration and participation. The main purpose of $\mathrm{SC}$ is to increase competitiveness whereas the purpose of $\mathrm{VE}$ is to exploit specific business opportunity. SC is stable and extends over a longer period of time, whereas VE is dynamic, ad-hoc and temporary and exists only for the lifetime of a specific business opportunity [7]. An extended enterprise can be seen as a particular case of a virtual enterprise [8].

An example is provided in the Figure 1. an intense use of information and communication technology (IS/IT).

Cash and Konsynski [12] coined the term "inter-organizational information system" (IOS) to refer to an automated IS shared by two organizations or more. An IOS is defined as a network-based IS that extends beyond traditional enterprise boundaries. As IOS permits information access to other organizations, the organizational boundary is redefined and extended to the extent that a firm's value chain needs to be redesigned [13].

Business organizations increasingly establish electronic links with their competitors or with firms in different industries to gain a competitive advantage [13].

Bakos [14] states that three characteristics are associated with IOS:

- first, it decreases the costs of exchanging and acquiring information by participating firms,

- second, the benefits for the IOS innovator increase as the number of firms joining the network increases,

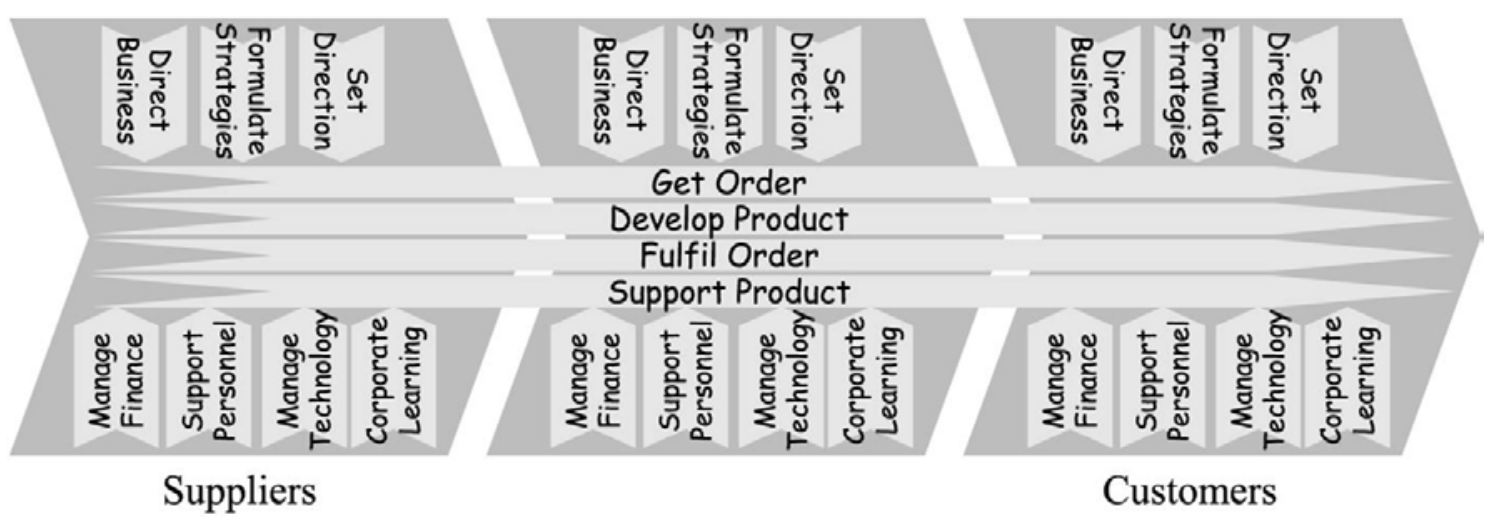

Figure 1. The extended business processes [9]

In the modern global competitive environment, manufacturing enterprises need active co-operation with a large network of suppliers and customers to form extended enterprises [10]. With inter-organizational networks, firms perceive the benefits derived from a vertical disintegration process which enables them to concentrate on their distinctive capacities, while identifying and developing mechanisms to improve the rapid configuration of operative structures to adapt to rapidly changeable environments [11]. Creating new organizational forms requires
- third, considerable switching costs are incurred when a firm shifts from one IOS to another.

Meanwhile, an IOS can be viewed in terms of its operational or strategic system support level. Farbey et al. [15] suggest that operational applications focus on process automation and primarily aim to save time and costs, while strategic applications are intended to achieve strategic goals and have the potential to transform entire businesses. In this paper we centre on the strategic level. 
The IOS can be modelled with an enterprise engineering approach.

Enterprise engineering (EE) involves analyzing, optimizing and re-engineering of all or part of business processes, information systems and organization structures in an enterprise or in an enterprise network [16]. According to Hoogervorst [17] this engineering approach offers important benefits such as:

1. The formal approach for addressing organized complexity and the realization of a unified and integrated design.

2. The formal identification of all coordination actions makes clear responsibilities.

These benefits generally do not appear with other business process modelling types. To ensure that this design is carried out coherently, the enterprise architecture concept arises. Enterprise architecture (EA) is defined as a way to structure and design a company's organization and operations. EA is a key issue in the development of enterprises supported by technology. EA should address more on how to align a business strategy to technology for implementation, and not just focus on business or IT with separate research and development [18]. dimensions and their power to provide solutions to challenges and problems in the business environment [20].

An IS/IT strategy should include the business needs for the future, which are to be aligned closely to the business strategy. It should also define and prioritise the investments needed to achieve the application portfolio [19]. The portfolio selection problem consists in how to allocate the capital to a number of goods in order to bring a most profitable return for investors [21]. Lederer and Gardiner [22] describe strategic information systems planning as "the process of identifying a portfolio of computer-based applications that will assist an organization in executing its business plans and realizing its business goals."

Business and IS/IT strategic alignment is the degree to which the IS/IT strategy supports, and is supported, by the business strategy [23], [24]. The classic Strategic Alignment Model (SAM) distinguishes between the business domain (business strategy and business infrastructure) and the technology domain (information strategy and IT infrastructure, including systems development and maintenance) in an organization [25], [26].

These domains can be identified in an extended enterprise. Figure 2 shows these domains located

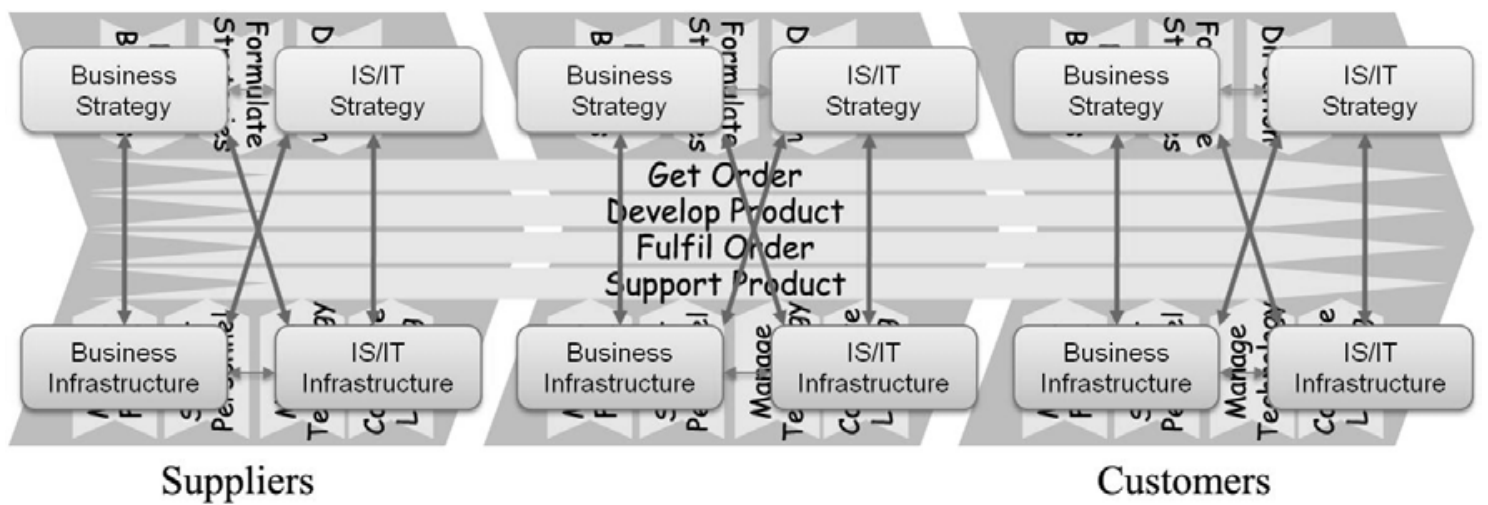

Figure 2. The strategic alignment model in each individual company of an extended enterprise

\section{Strategic Alignment}

Today, it is widely accepted that information systems knowledge is essential for managers because most organizations need information systems to survive and prosper [19]. To fully understand information systems, a manager must understand the broader organization, management, and information systems on the extended process of Figure 1 (grey figure).

As Figure 3 illustrates, on the one hand, the four domains for each individual company that compose the extended enterprise can be identified, while on the other hand, the four domains in the extended enterprise can also be identified. The business strategy and the IS/IT strategy for each individual company could differ from the business strategy and 
the IS/IT strategy in the extended enterprise. Thus, there must be a strategic alignment process inside each individual company, as well as, a strategic alignment process for the extended enterprise. enterprise and the development of the enterprise systems [29]. An enterprise architecture framework is applied to describe both the current (as-is) and future (to-be) states [30]. The framework should also simplify

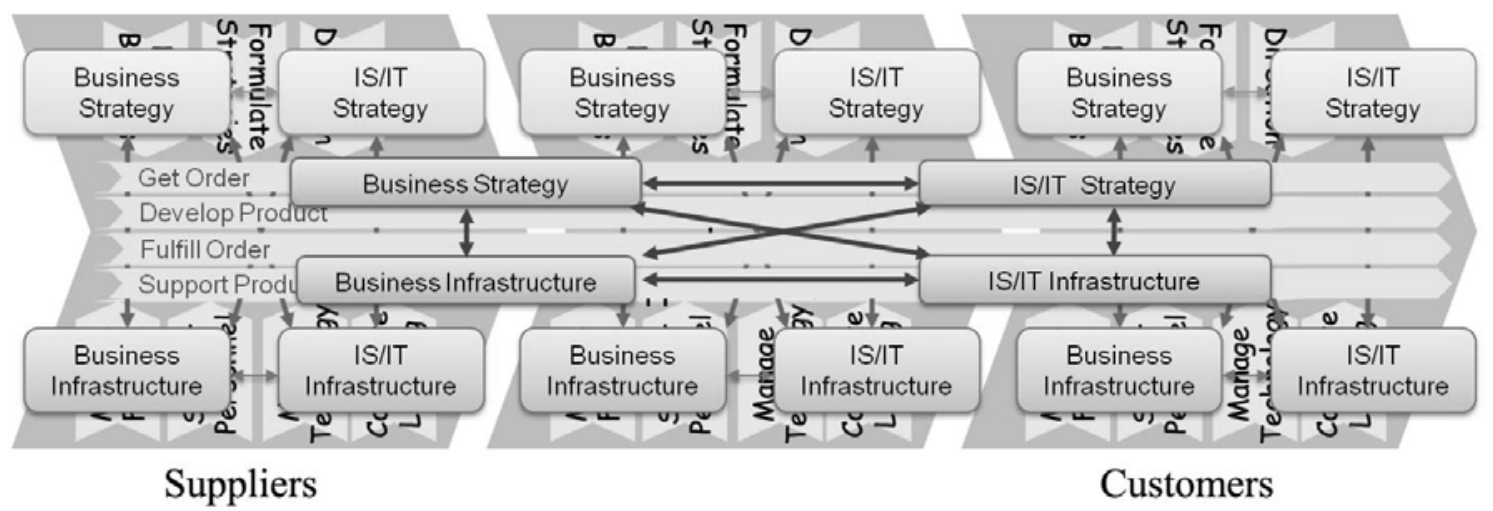

Figure 3. The strategic alignment model in extended enterprises

Luftman and Kempaiah [27] list three reasons for the ambiguity of alignment:

1. Alignment is often regarded as how IT is aligned to the business, but does not focus on how the business is aligned with IT.

2. Alignment has often been regarded to be a single issue item (e.g., the right technology), instead of being the result of multiple issues (e.g., an adequate implementation process, adaptations of business activities and data).

3. There are no adequate tools to assess alignment in an organization.

In order to solve these problems we propose extending the enterprise architecture framework to model and assess strategic alignment. The next section reviews the enterprise architecture framework from the alignment perspective.

\section{Enterprise Architectures and Modelling Framework Review}

Enterprise architecture is a coherent whole of the principles, methods and models that are used in the design and realization of the organizational structure, business processes, information systems, and infrastructure of a given enterprise [28].

The framework is a logical structure for classifying and organizing the descriptive representations of an enterprise that are significant for both the management of the the enterprise architecture development since it helps clarify how the different components of the architecture relate to each other. The framework should provide a general mechanism for defining views. Views are used in modelling because the complexity of an enterprise makes it unfeasible for a single descriptive representation to be comprehensible in its entirety [31].

Another adjacent concept to EA is Enterprise Modelling (EM). EM describes the EA from various viewpoints in detail to allow the specification and implementation of systems [18]. The use of these models in enterprise engineering can shorten design times and enhance modelling consistency [32].

Enterprise models have a life-cycle that relates the life cycle of the modelled entity. EM uses modelling languages, methods and tools chosen in accordance with the enterprise's lifecycle phase (or life-cycle activity). Today, there are several architecture frameworks, and they all have a modelling framework organizing enterprise model that may have to be created during a business entity's life [33].

All the enterprise architectures contain views in their frameworks. However, the life cycle, building blocks and how the building blocks fit together are not defined by them all [34].

IEEE 1471 [35] incorporates architecture viewpoints to codify the best practices for the creation and use of architecture views within an Architecture Description (AD). A viewpoint 
specifies the architecture concerns to be dealt with, the stakeholders addressed, and the languages, models, methods and techniques used to create, interpret and analyze any view (as a result of applying that viewpoint).

In 2006, IEEE 1471 was adopted by ISO as an international standard with an agreement to conduct a joint ISO and IEEE revision. The joint revision will be ISO/IEC 42010 (and IEEE Std 42010) under the new title: Systems and Software EngineeringArchitecture Description. One area deemed to be sufficiently mature to standardize is the notion of architecture framework. Each architectural description should have a clearly defined, explicitly stated architecture framework [36].

\section{Comparative Analysis}

The analysis has been carried out in the enterprise architectures TOGAF [37], GERAM [38], IE-GIP [39], Zachman [40], EAP [41], the reference architecture and methodology for virtual enterprises VERAM [42] and the reference model for collaborative networks ARCON [8]. The comparative analysis has been conducted in life-cycle phases (Identification, Conceptualization, Requirements Definition, Design, Implementation Description, Construction, Operation and Decommission) and modelling views (Business view, Information view, Data view, Application view, Technological view, Organizational view and Resource view).
We can summarize that some modelling views are included under the same name in the enterprise architecture frameworks analyzed. In other cases, the modelling views are included, but under a different name (e.g. organization view of GERAM corresponds with structural view of ARCON). Finally other views are not explicitly included, but can be complemented from other views. Similar conclusions were drawn from the life-cycle analysis (e.g. identification phase of GERAM corresponds with creation phase of ARCON).

Figure 4 depicts the relationships between modelling views and life-cycle phases. The Identification and Conceptualization phases do not take into account the Information, Resources, Data, Applications and Technological Views.

The Requirements Definition phase incorporates the Information, Resources and Data views. Applications and Technological views are only considered from Design Specification phase (to abbreviate Figure 4 does not include Operation and Decommission phases).

As discussed earlier, IS/IT is very important for the extended enterprises as is its alignment with business process and business strategies. Figure 4 illustrates that it is not possible to define aspects of information, resources, data, application and technology in early life-cycle stages.

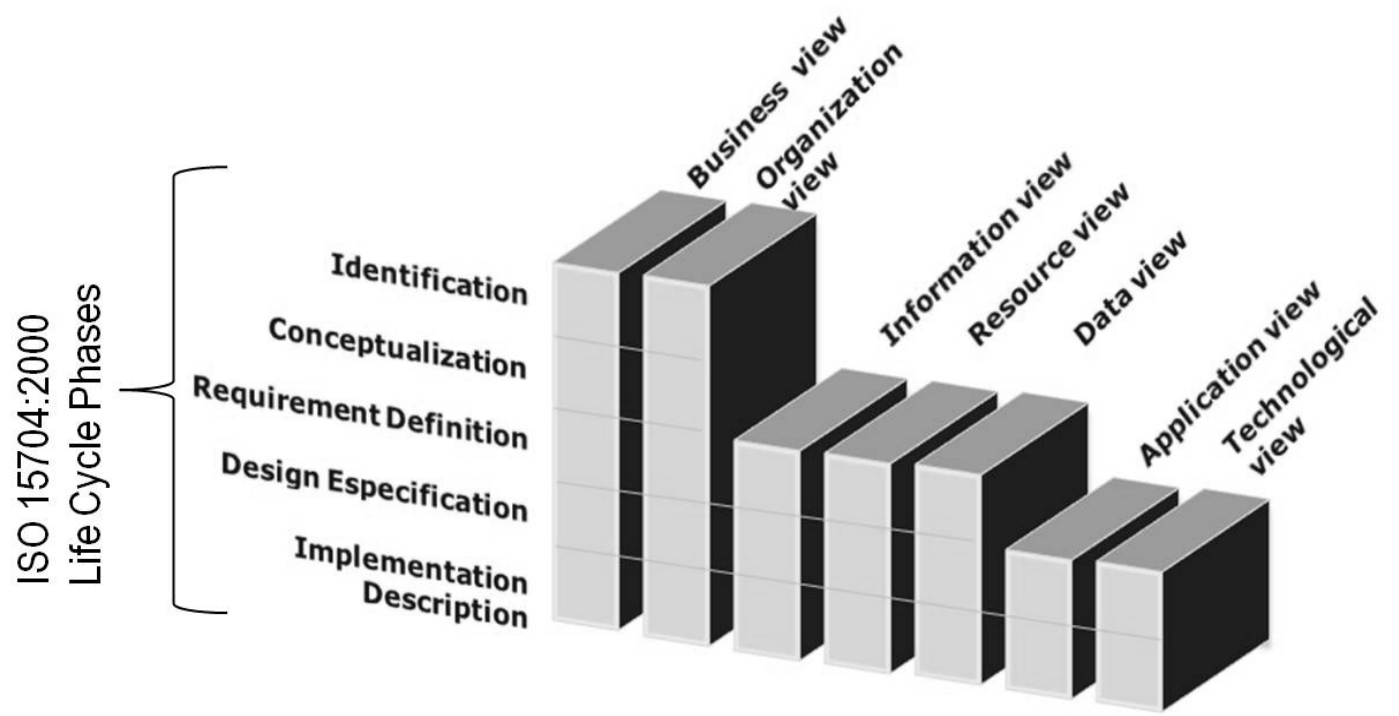

Figure 4. The incorporation of modelling views into the life-cycle phases of enterprise architectures 
Incorporating information systems and information technology into organizations involves considerable risks, and these risks increase when a strategic plan for its incorporation is not devised.

There are a number of proposals that relate alignment models with enterprise architectures [43], [44], [45], [46]. In most of cases, strategic alignment is conducted from the business strategy to organizational infrastructure. The IS/IT strategy is hardly defined and, when it is, it does not influence the business strategy. So, it is necessary to improve the definition of the IS/IT strategy and its alignment with the business strategy in EA.

According to Chen [47] the enterprise architecture approach does not define how to align and what to align. It is necessary to identify what elements, relating with the IS/IT strategy, must be included in the enterprise architecture framework.

These elements are:

- Defining and assessing business and IS/IT strategy alignment: there is no with the business entity [38]. It is necessary to incorporate the IS/IT definition into early phases [2].

- Incorporating an application and service portfolio: one element that promotes strategic alignment is the portfolio [49]. The strategy must be aligned and be transferred to the entire organization through portfolios, programmes and projects systematically, thus promoting the cohesion, visibility and effectiveness of communication [50].

- Incorporating the business and IT alignment maturity model: the alignment maturity assessment approach provides a comprehensive vehicle for organizations to assess business-IT alignment in terms of where they are and what they can do to improve alignment [51].

Table 1 shows these elements and checks if they are included or not in the analyzed enterprise architectures framework. In some cases, these elements are mentioned in the EA, but how to define them it is not identified (this case has been labelled as "Limited" in the table).

Table 1. IS/IT alignment components

\begin{tabular}{lccccccc}
\hline & Togaf & Geram & IE-GIP & Zachman & EAP & Veram & Arcon \\
\hline $\begin{array}{l}\text { IS/IT strategy definition } \\
\text { in } \begin{array}{l}\text { earlier life-cycle Limited } \\
\text { phases }\end{array}\end{array}$ & No & No & Limited & Limited & Limited & Limited \\
$\begin{array}{l}\text { Business and IS/IT } \\
\text { strategic alignment } \\
\text { assessment }\end{array}$ & Limited & No & Limited & Limited & Limited & Limited & Limited \\
$\begin{array}{l}\text { Application and services } \\
\text { portfolio }\end{array}$ & Limited & No & No & Limited & Limited & No & Limited \\
$\begin{array}{l}\text { Business and IS/IT } \\
\text { alignment } \\
\text { model }\end{array}$ maturity & No & No & No & No & No & No & No \\
\hline
\end{tabular}

consensus among academics and practitioners on how strategic alignment should be defined or measured in the organization, or what measures should be taken to maintain and improve it [48].

- Incorporating an IS/IT definition into earlier life-cycle phases: enterprise models have a life cycle that relates to the life cycle of the modelled entity. Initial phases (macro-level) contain a strategic definition, which is usually associated

\section{Enterprise Architecture Framework for Business and IS/IT Strategic Alignment in Extended Enterprises}

The identified IS/IT alignment components must be incorporated into the enterprise architecture framework in order to facilitate the IS/IT strategic definition and alignment with the business strategy in extended enterprises. 
We propose new building blocks according to IS/IT strategy components: IS/IT conceptualization, strategic dependencies, alignment heuristics, maturity model and, application portfolio (Table 2). These building blocks refer to Table 1 components. react with improvement actions in accordance with the answer. For example:

- Does our business understand IS/IT value?

Table 2. IS/IT alignment components and building blocks relationships

\begin{tabular}{|c|c|c|}
\hline Components & $\begin{array}{l}\text { Is it incorporated into the } \\
\text { proposed framework? }\end{array}$ & New building blocks defined \\
\hline $\begin{array}{l}\text { IS/IT strategy definition in } \\
\text { earlier life-cycle phases }\end{array}$ & Yes & $\begin{array}{l}\text { IS/IT Conceptualization } \\
\text { Strategic dependencies }\end{array}$ \\
\hline $\begin{array}{lr}\text { Business } & \text { and } \begin{array}{r}\text { IS/IT } \\
\text { strategic }\end{array} \\
\text { assessment } & \end{array}$ & Yes & $\begin{array}{l}\text { IS/IT Conceptualization } \\
\text { Alignment heuristics } \\
\text { Maturity Model }\end{array}$ \\
\hline $\begin{array}{l}\text { Application and services } \\
\text { portfolio }\end{array}$ & Yes & Application portfolio \\
\hline $\begin{array}{l}\text { Business and IS/IT } \\
\text { alignment maturity model }\end{array}$ & Yes & Maturity model \\
\hline
\end{tabular}

- IS/IT Conceptualization: the purpose of this building block is that it validates whether the IS/IT strategy is fully established for the individual company and for the extended enterprise (business entity). IS/IT conceptualization is a checklist to indicate what documents have been completed. Finally, a joint analysis with the business strategy must also be carried out. IS/IT objectives may precede the formulation of business objectives and will be used as input to their development.

- Strategic dependencies: the strategic dependencies model is based on the $\mathrm{i} *$ framework [51]. The strategic dependency building block represents the resource, task or goal dependencies among the different actors (roles, organizational units, organization cells or set of roles). It also indicates whether or not dependency is critical for the business entity. The purpose here is to detect dependencies among the actors. For the extended enterprise, the following organizations cells can be defined: suppliers, warehouse, manufactures, etc.

- Alignment heuristics: alignment heuristics are used in this case to detect weaknesses in the business and IS/IT alignment. By using this building block, different views are related by an alignment question. The participating enterprises of the extended enterprise will
- Does our business understand IS/IT value?

- Does IS/IT provide the appropriate level of value for the technology investment?

- Does the IS/IT area listen to the business users' needs?

- Does it prioritize their activities in line with the business requirements?

- Does IS/IT offer a competitive advantage?

- Maturity Model: it is based on the maturity models of [51] and [53], and allows the definition of the strategic alignment maturity level. The building block maturity model identifies the maturity level reached by the business entity in the extended enterprise. It is important to define the revision date and the last level assigned to analyze the alignment evolution.

- Application portfolio: this portfolio is divided into three building blocks:

- As-Is portfolio: the purpose of the asis portfolio is to support the information associated with each application and its relationships with the as-is business objectives in the extended enterprise.

- To-Be portfolio: the purpose of the to-be portfolio is to support the information associated with each application and its relationships with the to-be business objectives in the extended 
enterprise. There must be at least one relationship with a business objective.

- Application and services portfolio: this portfolio includes those that have been identified in the to-be portfolio and those which remain in the as-is portfolio. Each one can be associated with the business objectives and the business process that execute them in the extended enterprise. (business conceptualization phase), the as-is and to-be processes (business process definition), and an action plan was established to change the state (master plan). To facilitate the understanding of the lifecycle phases proposed and their integration in IE-GIP, a similar name has been assigned to the new phases but, in this case, IS/IT has been applied.

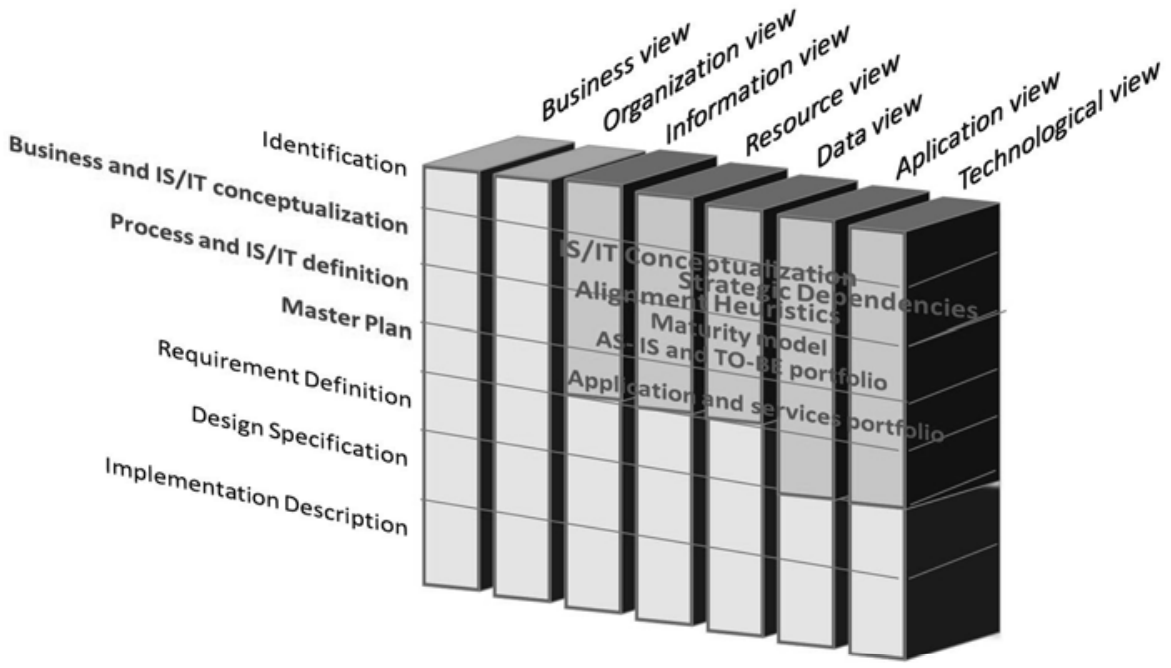

Figure 5. The proposed enterprise architecture framework

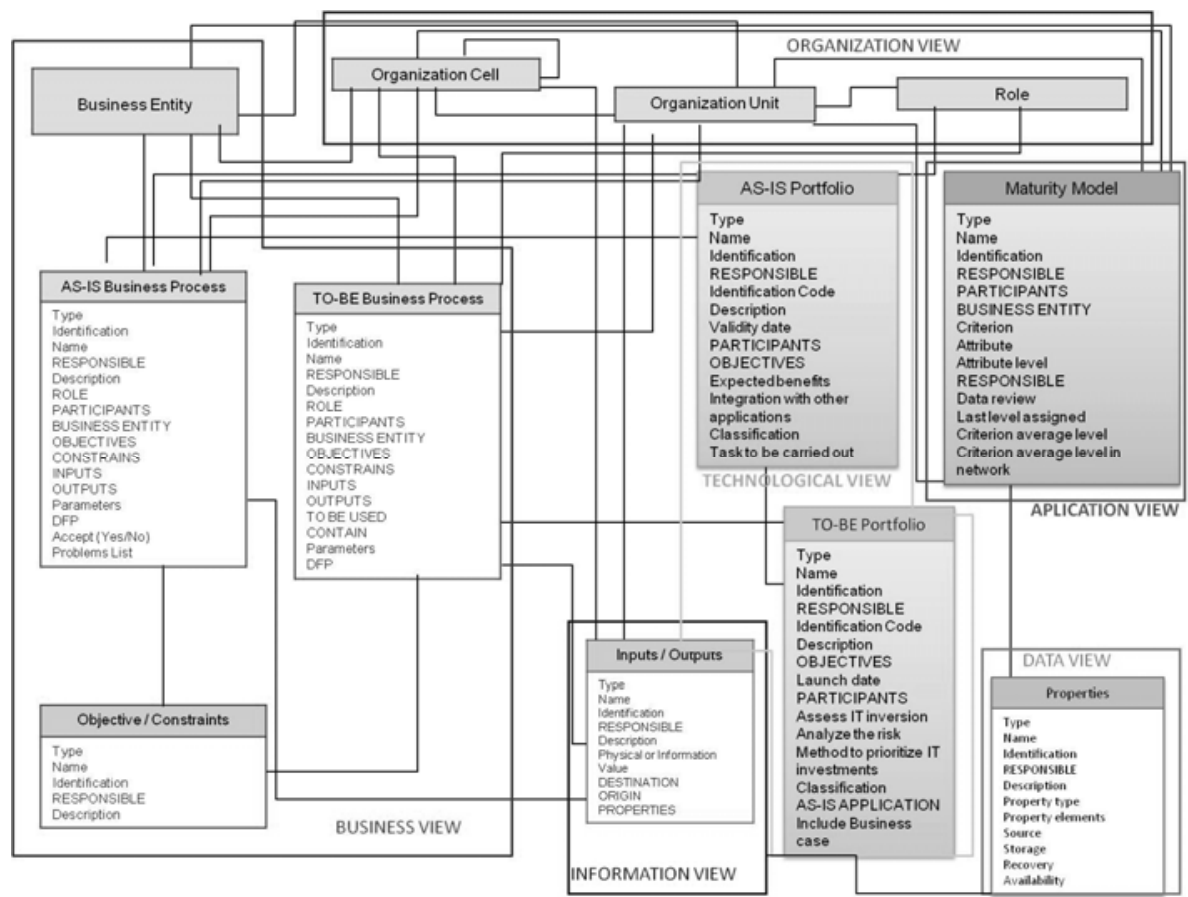

Figure 6. Building block relationships in the IS/IT process definition phase

On the other hand, we propose the definition of new phases: the conceptualization phase of GERAM [38] was extended in IE-GIP [39] to enable the definition of business strategy
Figure 5 shows how the modelling views and life-cycle phases have been extended in the proposed enterprise architecture framework. 
New building blocks can be included into the standard ISO 15704 associated to GERAM [38] and may relate to other building blocks. On the other hand the proposed building blocks can be used as a modelling language in the other architectures.

For example, Figure 6 shows the relationships between the building blocks and, therefore, between the modelling views in the IS/IT process definition phase. A capital letter indicates that the component refers to another building block.

\section{Case Study}

This proposal has been applied in a ceramic tile company. It was necessary to identify the components of an extended manufacturing process.

Collaborative order management was the selected business entity because it is a critical process for the company. Information systems and information technology are essential to support this process. Two organization cells were identified in the IT area: the IT Board (comprising the CIO and the CFO organization units), and the Steering Committee (comprising the CIO, the CFO, the external consultancy manager and the data manager organization unit).

Business and IS/IT conceptualization was carried out after identifying the business entity. Not all the organization units from the business and IS/IT area contributed to conceptualization, as expected; defining the alignment heuristics led to the identification of those aspects that were not well resolved in conceptualization.

The strategic dependencies model helped to identify the dependencies among the actors, and detected bottlenecks and vulnerabilities. First, the actors involved were identified: suppliers, manufacturers, wholesalers and customers (bringing together retailers and end customers). Besides these actors, we proposed a new one to be modelled, the computer system, which includes the information system and technology to be used; in this way, the strategic relationships with it can be modelled. Dependencies between two actors are modelled without having to analyze the actions carried out by each depending actor in order to meet the dependency objective (objective, resource or task).

The application and services portfolio has enabled the participating companies to link the enterprise business processes to applications and services at the macro-level through goals. It has also helped prioritize applications.

The maturity model has allowed a detailed analysis of the alignment between business and IS/IT, with values from one to five where one is the lowest value. For this particular case, 43 attributes were identified and classified as 6 criteria. Examples of these attributes are: the inter-organizational business objectives shared, interorganizational communication, interorganizational strategy, associated, in this case, with the communication criterion.

\section{Conclusion}

This paper reports the needs for a modelling framework that includes information and communication technology in the early lifecycle phases in extended enterprises. Traditionally, the business strategy has been the driver of organization and IT infrastructure. Alignment it is not concerned with the exploitation of emerging IT capabilities to impact new products and services; technology is not seen as a competitive advantage.

Hence it is necessary to extend all the modelling views to all the life-cycle phases and to define the strategic alignment components.

The proposed framework helps define the IS/IT strategy, the business and IS/IT alignment assessment, incorporate the IS/IT definition into earlier life-cycle phases, incorporate the application and services portfolio and to incorporates the business and IT alignment maturity model by means of the following blocks: IS/IT conceptualization, alignment heuristics, strategic dependencies, maturity model and as-is portfolio, to-be portfolio and application and service portfolio.

The utilization of building blocks enables them to be integrated with other enterprise modelling constructs and provides greater flexibility for their definition. 
Its application to an extended process, (collaborative order management), has enabled the validation of the framework's utility.

\section{REFERENCES}

1. CHOI, Y., D. KANG, H. CHAE, K. KIM, An Enterprise Architecture Framework for Collaboration of Virtual Enterprise Chains, International Journal of Advanced Manufacturing Technology, vol. 35, 2008, pp. 1065-1078.

2. CUENCA, L., A. BOZA, A. ORTIZ, Enterprise Architecture Framework with Early Business/ICT Alignment for Extended Enterprises. Balanced Automation Systems, vol. 322, Springe, 2010, pp. 11-18.

3. VASILIU, L., J. BROWNE, An Integrated Modelling Approach of the Extended Enterprise Using Fractals, Game Theory and Neural Networks Structure, Proceedings of 9th International Conference of Concurrent Enterprising, Espoo, Finland, June 16-18, 2003.

4. ZHANG, J., J. BROWNE, Extended and Virtual Enterprises - Similarities and Differences. International Journal of Management Systems, 1999.

5. FILOS, E., Virtuality and the Future of Organizations, Virtual Enterprise Integration: Technological and Organizational Perspectives, Chapter 2, pp. 32-46. Idea Group Publishing, Hershey, USA. 2005, in: Goel, A., Schmidt, H.; and Gilbert, D., Formal Models of Virtual Enterprise Architecture: Motivations and Approaches, PACIS 2010 Proceedings, Paper 117.

6. PIRES, S., C. BREMER, L. DE SANTA, E. GOLART, Supply Chain and Virtual Enterprises: Comparisons, Migration and a Case Study. International Journal of Logistics, vol. 4(3), 2001, pp. 297-311.

7. CAMARINHA-MATOS, L., H. AFSARMANESH, Collaboration forms, Camarinha 2008 collaborative, Chapter 2.3, pp. 51-66, in Goel, A., Schmidt, H. and Gilbert, D., Formal Models of Virtual Enterprise Architecture: Motivations and
Approaches, PACIS 2010 Proceedings, Paper 117

8. ECOLEAD D52.2 Rough Reference model for Collaborative Networks, http://www.ve-forum.org/projects/284/

Deliverables/D52.2_Final.pdf, 2006

9. BITTICI, U. S., K. MENDIBIL, V. MARTINEZ, P. ALBORES, Measuring and Managing Performance in Extended Enterprises, International Journal of Operations \& Production Management. Bradford: Vol.25, Iss. 3/4; 2005, p. 333.

10. CHENG, K., POPOV, Y.: InternetEnabled Modelling of Extended Manufacturing Enterprises Using Process-Based Techniques. International Journal of Advanced Manufacturing Technology, vol. 23, 2004, pp. 148-153.

11. CAMARINHA-MATOS, L. M., $\quad \mathrm{H}$. AFSARMANESH, Collaborative Networks: A New Scientific Discipline, Journal of Intelligent Manufacturing, vol. 16(4), 2005, pp. 439-452.

12. CASH, J. I., B. R. KONSYNSKI, IS Redraws Competitive Boundaries, Harvard Business Review, March-April 1985, pp. 134-142.

13. HONG, I. B., A New Framework for Inter-organizational Systems Based on the Linkage of Participants' Roles Information \& Management 39, 2002, pp. 261-270.

14. BAKOS, J. Y., A Strategic Analysis of Electronic Marketplaces, MIS Quarterly, vol. 15, 1991, pp. 295-310.

15. FARBEY, B., F. F. LAND, D. TARGETT, A Taxonomy of Information Systems Applications: The Benefits' Evaluation Ladder, European Journal of Information Systems, vol.4(1), 1995, pp. 41-50.

16. VERNADAT, F., Enterprise Modelling and Integration, Principles and Applications. Chapman \& Hall, Boca Raton, 1996.

17. HOOGERVORST, J., Enterprise Governance and Enterprise Engineering, Springer, Heidelberg, 2009. 
18. CHEN, D., G. DOUMENINGTS, F. VERNADAT, Architectures for Enterprise Integration and Interoperability: Past, Present and Future, Computers in Industry 59, 2008, pp. 647-659.

19. ISSA-SALWE, A., M. AHMED, K. ALOUFI, M. KABIR, Strategic Information Systems Alignment: Alignment of IS/IT with Business Strategy. Journal of Information Processing Systems, vol. 6(1), 2009.

20. BHATNAGAR, A., Strategic Information Systems Planning: Alignment of IS/IT Planning and Business Planning, Unitec, New Zealand, 2007.

21. ANDREICA, M. E., I. DOBRE, M. I. ANDREICA, C. RESTEANU, A New Portfolio Selection Method Based on Interval Data, Studies in Informatics and Control, vol. 19,(3), 2010, pp. 253-262.

22. LEDERER, A. L., V. GARDINER, Strategic Information Systems Planning: The Method/1 Approach. Information Systems Management, vol. 9(3), 1992, pp. 13-20.

23. LUFTMAN, J. N., P. R. LEWIS, S. H. OLDACH, Transforming the Enterprise: The Alignment of Business and Information Technology Strategies. IBM Systems Journal, vol. 32(1), 1993, p. 198.

24. REICH, B., I. BENBASAT, Factors that Influence the Social Dimension of Alignment between Business and IT Objectives. MIS Quarterly vol. 24(1), 2000, pp. 81-113.

25. HENDERSON, J. C., N. VENKATRAMAN, Strategic Alignment: Leveraging Information Technology for Transforming Organizations, IBM Systems Journal, vol. 32(1), 1993, pp. 472-484.

26. SMITS M., M. FAIRCHILD, P. RIBBERSS, K. MILIS, E. VAN GEEL, Assessing Strategic Alignment to Improve IT Effectiveness 22nd Bled eConference eEnablement: Facilitating an Open, Effective and Representative eSociety, 2009.
27. LUFTMAN, J. N., R. KEMPAIAH, An Update on Business-ITt Alignment: A Line Has Been Drawn, MISQE, vol. 6(3), 2007, pp. 165-177.

28. LANKHORST, M. M., Enterprise Architecture Modeling - The Issue of Integration. Advanced Engineering Informatics. Engineering Computing and Technology vol. 18(4), 2004, p. 205.

29. INMON, W. H., J. A. ZACHMAN, G. J. GEIGER, Data Stores, Data Warehousing and the Zachman Framework. McGraw-Hill, New York, 1997.

30. TANG, A., J. HAN, P. CHEN, A Comparative Analysis of Architecture Frameworks. Technical Report SUTITTR2004.01, Swinburne University of Technology, 2004.

31. MARTIN, R., E. ROBERTSON, Architectural Principles for Enterprise Frameworks, 2004.

32. CHEN, D., F. VERNADAT, Standard on Enterprise Integration and Engineering-State of the Art, International Journal of. Computer Integrated Manufacturing vol. 17(3), 2004, pp. 235-253.

33. BERNUS, P., L. NEMES, G. SCHMIDT, Handbook on Enterprise Architecture. Springer, Berlin, 2003.

34. CUENCA L. L., A. ORTIZ, A. BOZA, Business and IS/IT Strategic Alignment Framework, Emerging Trends in Technological Innovation vol. 314, Springer, 2010, pp. 24-31.

35. ISO. ISO/IEC 42010 Systems and Software Engineering - Architectural Description, July 2007.

36. EMERY D., R. HILARD, Every Architecture Description Needs a Framework: Expressing Architecture Frameworks Using Iso/Iec 42010. WICSA/ECSA 2009.

37. TOGAF The Open Group Architecture Framework, http://www.opengroup.org/togaf

38. IFIP-IFAC Task Force, Generalized Enterprise Reference Architecture and 
Methodology, Version 1.6.2, Annex to ISO WD15704, IFIP-IFAC Task Force, 1999.

39. ORTIZ, A., F. LARIO, L. ROS, IE-GIP. A Proposal for a Methodology to Develop Enterprise Integration Program. Computers in Industry vol. 40, 1999, pp. 155-171.

40. SOWA, J., J. ZACHMAN, Extending and formalizing the framework for information-systems architecture. IBM Systems Journal 31(3), 1992, p. 590.

41. SPEWAK, S., Enterprise Architecture Planning: Developing a Blueprint for Data, Applications, and Technology, Wiley, Chichester, 1993.

42. ZWEGERS A., M. TOLLE, J. VESTERAGER, VERAM, http://cic.vtt.fi/projects/globemen/book/0 1_zwegers2.pdf

43. WEGMANN, A., P. BALABKO, L. LE, G. REVEG, I. RYCHKOVA, A Method and Tool for Business - IT Alignment, in Enterprise Architecture Proceedings of the CAISE. Porto University, Porto, Portugal, 2005.

44. PEREIRA, C., P. SOUSA, Enterprise Architecture: Business and IT Alignment, in ACM Symposium on Applied COMPUTING, 2005.

45. PLAZAOLA, L., J. FLORES, E. SILVA, N. VARGAS, M. EKSTEDT, An Approach to Associate Strategic Business-IT Alignment Assessment to Enterprise Architecture, in Conference on Systems Engineering Research, Stevens Institute of Technology Campus, USA, 2007.
46. WANG, X., X. ZHOU, L. JIANG, A Method of Business and IT Alignment Based on Enterprise Architecture, 2008.

47. CHEN, H. M., SOA, Enterprise Architecture and Business-IT Alignment: An Integrated Framework. In: Proceedings of the 6th International Workshop on System/Software Architectures, 2007.

48. SILVA, E., L. PLAZAOLA, M. EKSTEDT, Strategic Business and IT Alignment, A Prioritized Theory Diagram, Proceedings of PICMET06, Istanbul, Turkey, 2006.

49. COOPER, R. G., S. J. EDGETT, E. J. KLEINSCHMIDT, Portfolio Management for New Products. 1st ed. MA, Perseus Books, 1998.

50. MORRIS, P., A. JAMIESON, Moving from Corporate Strategy to Project Strategy, Project Management Journal, vol. 36(4), 2005, pp. 5-18.

51. LUFTMAN, J., Assessing Business-IT Alignment Maturity. Communications of the Association for Information Systems vol. 4(14), 2000.

52. YU, E., Modeling Strategic Relationships for Process Reengineering, Ph.D. thesis, 1995.

53. SANTANA, R. G., M. DANEVA, P. A. T. VAN ECK, R. J. WIERINGA, Towards a Business-IT Alignment Maturity Model for Collaborative Networked Organizations, in Proceedings of the International Workshop on Enterprise Interoperability Munich, Germany, 2008, pp. 70-81. 